\title{
Tip 2 Diyabetlilerde Metabolik Kontrol ve Komplikasyonlarla Segmental Vücut Yağ Dağılımı Arasındaki İlişki
}

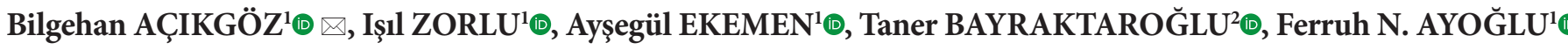 \\ ${ }^{1}$ Zonguldak Bülent Ecevit Üniversitesi Tip Fakültesi, Halk Sağlı̆̆ Anabilim Dalı, Zonguldak \\ ${ }^{2}$ Zonguldak Bülent Ecevit Üniversitesi Tip Fakültesi, İç Hastalıkları Anabilim Dalı, Zonguldak
}

Bu makaleye yapılacak atıf: Açıkgöz B, Zorlu I, Ekemen A, Bayraktaroğlu T, Ayoğlu FN. Tip 2 Diyabetlilerde Metabolik Kontrol ve Komplikasyonlarla Segmental Vücut Yağ Dağılımı Arasındaki İlişki. Türk Diyab Obez 2019;1: 23-30.

\begin{abstract}
ÖZET
Amaç: Diyabetli hastalarda metabolik kontrol ve komplikasyonlarla segmenter vücut yağ dağılımı arasındaki ilişkinin belirlenmesi amaçlanmıştır.

Gereç ve Yöntemler: Bu kesitsel çalışmada Zonguldak Bülent Ecevit Üniversitesi Obezite ve Diyabet Uygulama ve Araştırma Merkezi’ne 6 Nisan 2017 tarihinden 21 Mart 2018 tarihine kadar başvuran 485 tip 2 diabetes mellitus hastasının dosyaları incelenmiştir. Hastaların sosyodemografik verileri, hastalık süresi, açlık kan şekeri, glikolize hemoglobin değeri, lipid profili, komplikasyonlar, antropometrik ölçümler, vücut yağ dağılımları ve beslenme, egzersiz ve uygulanan tedavi tipleri kaydedilerek analizler yapılmışır.

Bulgular: Hastaların \%59,6 ( $\mathrm{n}=289)$ 'sı kadın ve \%40,4 ( $\mathrm{n}=196)$ 'ü erkekti. Son tetkiklerinde, hastaların \%92,9'unun açlık kan şekeri, $\% 61,1$ 'inin total kolesterolü, \%54,2'sinin trigliserid (TG) düzeyi ve \%49,1'inin düşük dansiteli lipoprotein kolesterolü (LDL-k) düzeyi normalin üzerindeydi. Glikozile hemoglobin (HbAlc) değeri hastaların \%74,9'unda \%6,5'in ve \%62,9'unda \%7,0'in üzerinde saptandı. En az bir komplikasyonu olanların hastalık süresi, bel çevresi, açlık kan şekeri, beden kütle indeksi (BKI) ortalamaları komplikasyonu olmayanlardan anlamlı derecede yüksekti $(\mathrm{p}<0,05)$. Yaşa göre total vücut yağ oranları değerlendirildiğinde; kadınların \%11,0’i normal, \%26,0’ı aşırı yağlı, \%62,3’ü obez, erkeklerin \%15,8'i normal, \%37,2'si aşırı yağlı ve \%46,0’ı obez olarak saptandı. Egzersiz yapanların total vücut yağ oranı ortalaması $\% 35,5 \pm 10,0$ iken yapmayanların $\% 37,7 \pm 9,5$ idi. Farklı tedavi prosedürlerine göre hastalık süresi bir yıl altı, 1-5 yll, 5-10 yıl, 10 yıl ve üzeri olanlar arasında total vücut yağ oranları açısından anlamlı fark yoktu ( $>>0,05)$.

Sonuç: Çalışmamızın sonuçlarına göre Tip 2 diyabet hastalarının çoğunluğunun obez olduğu, egzersiz yapanlarda total vücut yağ oranının anlamlı düşük olduğu, en az bir komplikasyonu olanların hastalık süresi, bel çevresi, açlık kan şekeri, beden kütle indeksi ortalamalarının anlamlı yüksek olduğu tespit edildi. Obezite ve diabetes mellitusun tanı, tedavi ve takibi yapılırken antropometrik parametreler, vücut yağ oranı dağılımı, tedavi süreçleri ve metabolik durum önemli bir etkileşim içerisindedir. Hastalıkları yönetirken beraber değerlendirildiği durumlarda daha anlamlı sonuçlara ulaşılacağından her biri dikkate alınmalıdır.
\end{abstract}

Anahtar Sözcükler: Tip 2 diabetes mellitus, Obezite, Biyoelektrik impedans, Vücut yağ dağılımı

\section{The Relationship Between Metabolic Control and Complications and Segmental Body Fat Distribution in Type 2 Diabetics}

\begin{abstract}
Aim: The aim of this study was to determine the relationship between metabolic status and complications and distribution of body fat in diabetic patients.

Material and Methods: In this cross-sectional study files of 485 type 2 diabetes mellitus patients who applied to Zonguldak Bulent Ecevit University Obesity and Diabetes Research and Application Center between 6 April 2017 and 21 March 2018 were examined.
\end{abstract}

Bu araştırma 13-17 Kasım 2018 tarihinde Antalya'da düzenlenen 2. Uluslararası-20. Ulusal Halk Sağlığı Kongresi’nde sözel bildiri olarak sunulmuştur.

ORCID: Bilgehan Açıkgöz / 0000-0002-1405-5841, Işıl Zorlu / 0000-0001-9649-572X, Ayşegül Ekemen / 0000-0003-4764-9678, Taner Bayraktaroğlu / 0000-0003-3159-6663, Ferruh N. Ayoğlu / 0000-0003-3266-1519 
Sociodemographic data, duration of disease, fasting blood glucose, gylcated hemoglobin, lipidprofil, complications, biometric measurements, body fat distribution and diet, exercise and type of treatment were recorded and analyzed.

Results: In our study population, 59.6\% $(n=289)$ of the patients were female and $40.4 \%(n=196)$ were male. In the last examinations, 92.9\% of the patients had a fasting blood glucose, $61.1 \%$ had total cholesterol, $54.2 \%$ had TG and $49.1 \%$ had LDL-k levels higher than normal. In $74.9 \%$ of patients, gylcated hemoglobin was found to be higher than $6.5 \%$ and in $62.9 \%$ of them was higher than $7.0 \%$. Patients with at least one complication had higher disease duration, waist circumference, fasting blood glucose, body mass index averages than those without complication ( $\mathrm{p}<0.05$ ). When total body fat ratios were evaluated by age, $26.0 \%$ of women were overfat, $62.3 \%$ were obese, $37.2 \%$ of males were overfat, $46.0 \%$ were obese. The total body fat ratio of those who exercise is lower than those who do not. Different treatment procedures and disease duration do not affect total body fat ratios $(\mathrm{p}>0.05)$.

Conclusion: According to the results of our study, most of the type 2 diabetes patients were obese. Total body fat was lower in the patients who exercised. Patients with at least one complication had higher disease duration, waist circumference, fasting blood glucose, body mass index averages. While the diagnosis, treatment and follow-up of obesity and diabetes mellitus, anthropometric parameters, body fat ratio distribution, treatment processes and metabolic status are important interactions. When evaluating the diseases together, each one should be taken into consideration as more meaningful results will be obtained.

Key Words: Type 2 Diabetes Mellitus, Obesity, Bioelectric Impedance, Body Fat

\section{GíRIŞ}

Diabetes mellitus (DM), insülin eksikliği ya da insülin etkisindeki defektler nedeniyle organizmanın karbonhidrat, yağ ve proteinlerden yeterince yararlanamadığı, sürekli tıbbi bakım gerektiren kronik bir metabolizma hastalığıdır (1). İlk kez 1970’lerde halk sağllğı sorunu olarak tanımlanan diyabet, sıklığı ve yarattığı sorunlar nedeniyle tüm dünyada önemi gittikçe artan, hastaya ve topluma büyük yük oluşturan bir sağlık sorunudur (2). Dünya Sağlık Örgütü (WHO) tarafından derlenen veriler dünya çapında yaklaşık 150 milyon kişinin DM hastası olduğunu ve bu sayının 2025 yılına kadar iki katına çıkabileceğini göstermektedir. Bu artışın büyük kısmı gelişmekte olan ülkelerde meydana gelecektir. Nüfus artışı, yaşlanma, sağlıksız beslenme, obezite ve yaşam tarzları bunda etkili olacaktır (3). Yaşam tarzındaki hızlı değişim ile birlikte gelişmiş ve gelişmekte olan toplumların tümünde, özellikle tip 2 diyabet prevelansı hızla yükselmektedir (4-7). Dünya Sağlı Örgütü’nün 2016 yılı istatistiklerine göre diyabet 'bulaşıcı olmayan hastalıklara' bağlı ölümlerde 1,6 milyon ölüm ile dördüncü sirada yer almaktadır (8). Türkiye'de TURDEP-II verilerine göre nüfusun \%13,7'si diyabet hastasıdır (9).

Diyabet tedavisinde glisemik kontrol, yani metabolik kontrolün sağlanması diyabete bağlı gelişen komplikasyonların önlenmesi için önemlidir. Tip 1 ve tip 2 DM'li hastalarda metabolik kontrol yetersiz olduğunda, mikrovasküler (nefropati, nöropati, retinopati) ve makrovasküler (kardiyovasküler hastalık, serebrovasküler hastalık, periferik damar hastalığı, diyabetik ayak vb.) komplikasyonlar ortaya çıabilmektedir $(10,11)$. Ayrıca, diyabet hastalarında hipertansiyon, dislipidemi, obezite gibi hastalıklar diyabeti olmayanlara göre 2-4 kat daha fazla bildirilmektedir (12).

Obezite, Tip 2 diyabete çoğunlukla eşlik etmesinin yanında, kişide diyabet gelişeceğini belirleyen önemli bir risk faktörüdür. Tüm obezlerde tip 2 diyabet olmasa da, bu hastaların büyük çoğunluğu obezdir. Ayrıca insulin direnci ile obezite arasında, neden sonuç ilişkisi konusunda da kesin bir görüş birliği yoktur. Ancak, özellikle abdominal obezite ile insulin direnci arasında sıkı ilişki varlığı bilinen bir gerçektir (13).

Vücut yağ dağılımı ve toplam yağ oranı, diyabet ve kardiyovasküler hastalıklarla ilişkilidir (14-17). Diabetes mellitus metabolik bir hastalık olması sebebiyle vücut kompozisyonu bileşenleri etkilenmektedir $(18,19)$.

Literatürde diyabetli hastalarda vücut yağ yüzdesi, metabolik durum ve komplikasyonlarını inceleyen çok sayıda çalışma bulunmakla birlikte, bunların ilişkisini bir arada inceleyen çalışmalar görece sınırlıdır. Bu çalışmada diyabetli hastalarda metabolik durum ve komplikasyonlar ile vücut yağ dağılımı arasındaki ilişkinin belirlenmesi hedeflenmiştir.

\section{GEREÇ ve YÖNTEMLER}

Araştırma, Bülent Ecevit Üniversitesi Tıp Fakültesi Klinik Araştırmalar Etik Kurulu'ndan alınan etik kurul iznini takiben başlatıldı. Bu kesitsel araştırma Zonguldak Bülent Ecevit Üniversitesi Obezite ve Diyabet Uygulama ve Araştırma Merkezi'nde yapılmıştır. İlk hasta kabulünü 6 Nisan 2017 tarihinde yapan Merkez'de 21 Mart 2018 tarihine kadar izlenen Tip 2 diabetes mellituslu 500 olgunun verileri hasta dosyalarından elde edilmiştir. Araştırmada örneklem seçilmemiş olup dosyalarında eksiklik bulunan 15 olgu çalışma dışı bırakılmış ve 485 (\%97,0) olgu çalışmaya dahil edilmiştir.

Olguların sosyodemografik verileri, hastalık süresi, biyometrik ölçümler (boy, kilo ve bel çevresi), vücut yağ yüzdesi dağılımları, son tetkiklerindeki açlık kan şekeri 
(AKŞ), HbA1c, lipid profili [TG, yüksek dansiteli lipoprotein kolesterolü (HDL-k), LDL-k, total kolesterol], beslenme, egzersiz ve uygulanan tedavi tipi [oral anti diyabetik (OAD), insülin, kombine tedavi] kaydedilmiştir. Yine diyabete bağlı komplikasyonları albüminüri, retinopati, nefropati, nöropati, koroner arter hastalığı, periferik arter hastalığ 1 , serebrovasküler olay (SVO), diyabetik ayak varlığ 1 kaydedilmiştir.

Olguların vücut yağ yüzdesi dağılımları biyoelektrik impedans analiz (BIA) sistemini kullanan TANITA (BC418MA) cihazı ile değerlendirilmiștir. Sekiz elektrot, $50 \mathrm{kHz}$ sabit akımla ("hand to hand, foot to foot"), beş ayrı akım dalgası ile çalışan cihazla beş ayrı bölge için (sağ ve sol kol, sağ ve sol bacak, gövde) yağ oranı, kas kütlesi ve yağsız kütle değerleri tespit edilmiştir. Cihaz ile ölçülen total vücut yağ oranları yaş ve cinsiyete göre düşük yağlı, normal, aşırı yağlı ve obez olarak sınıflandırılmıştır (20).

\section{İstatistiksel Analiz}

Tanımlayıcı istatistikler; sayı, yüzde, minimum-maksimum değerler ve ortalama \pm standart sapma şeklinde sunulmuştur. Gruplar arası karşılaştırmalarda Ki-Kare Testi, iki ortalama arasındaki farkın önemlilik testi, Mann-Whitney U Testi, Anova Varyans Analizi, Kruskal-Wallis Varyans Analizi kullanılmış, $\mathrm{p}<0,05$ değeri anlamlı olarak kabul edilmiştir.

\section{BULGULAR}

Çalışmaya 485 tip 2 diabetes mellitus olgusu alınmıştır. Olguların yaş ortalaması 55,5 $\pm 9,9$ (min: 20, max: 84 ), \%59,6 $(\mathrm{n}=289)^{\prime}$ 's 1 kadın ve $\% 40,4 \quad(\mathrm{n}=196)^{\prime}$ '̈ erkektir. Ortalama hastalık süresi 103,1 $\pm 91,3$ ay (min:1, max:480)'dır. Hastalık süresi $<1$ yıl olanlar $\% 9,5,1-5$ yıl arasinda olanlar $\% 27,5$, $5-10$ yll olanlar $\% 22,7$ ve $\geq 10$ yıl ve üzeri olanlar $\% 40,3$ olarak saptanmıştır. Olguların \%41,4’ü yeterli egzersiz yaparken $\% 42,2$ 'si beslenmeye yeterli dikkat etmektedir. Ayrıca \%62,8'i yalnız OAD, \%11,2'si yalnız insülin, \%19,4'ü kombine ilaç tedavisi alırken \%6,6'sı ilaç kullanmamaktadır.

Olguların son tetkiklerine bakıldığında \%92,9'unun açlık kan şekeri, \%61,1'inin total kolesterolü, \%54,2'sinin TG düzeyi, \%49,1'inin LDL-k düzeyi normalin üzerinde ve \%74,9 unun $\mathrm{HbA1c}$ değeri \%6,5' in üzerinde saptanmıştır. Diyabetik olgularımızın \%62,9 unun HbA1c değeri \%7,0'1n üzerinde saptanmıştır.

Olgulara ait BKİ ortalamasi $34,4 \pm 7,5$ olup \%6,6'sinin ağırlığ1 normal, \%24,9’unun aşırı kilolu ve \%68,5’i obezdi. Kadınların bel çevresi ortalaması $107,7 \pm 14,4 \mathrm{~cm}$ iken erkeklerin 105,3 $\pm 13,3 \mathrm{~cm}$ saptand (Tablo 1). Kadınların yaşa göre total vücut yağ oranları değerlendirildiğinde \%11,0'i normal, \%26,0'1 aşırı yağlı, \%62,3'ü obez olarak saptanmıştır. Erkeklerin yaşa göre total vücut yağ oranları değerlendirildiğinde; \%15,8'i normal, \%37,2'si aşırı yağlı, \%46,0'1 obez olarak saptanmıştır.

Olguların \%31,8'inde en az bir komplikasyon mevcuttu. Ayrıca \%12,0'ında albüminüri, \%2,5'inde retinopati, $\% 7,2$ 'sinde nefropati, \%9,5'inde nöropati, \%11,8'inde koroner arter hastalığı, \%5,4'ünde periferik arter hastalığ 1 , $\% 0,6$ 'sında SVO öyküsü ve \%0,8'inde diyabetik ayak olduğu saptandı. En az bir komplikasyon bulunan hastalar ile komplikasyonsuz hastaların hastalık süresi, bel çevresi, AKŞ ve BKİ ortalamaları arasında anlamlı fark varken, HbA1c, total kolesterol, TG, HDL-k ve LDL-k ortalamaları arasındaki fark anlamlı değildir (Tablo 2). Gelişen komplikasyona göre bel çevresi, BKİ, total vücut yağ oranı ortalamaları Tablo 3'te sunulmuştur.

Cinsiyet, egzersiz, diyet, HbAlc, AKŞ, total kolesterol, TG, LDL, HDL, komplikasyonlara göre, total vücut yağ oranı ortalamaları Tablo 4’te sunulmuştur. Kadınların total vücut

Tablo 1: Hastaların yaş, hastalık süresi, HbA1c, Total kolesterol, TG, LDL-k, HDL-k, bel çevresi, BKİ düzeyleri.

\begin{tabular}{|c|c|c|c|c|}
\hline & & $\mathbf{n}$ & Ort. \pm Ss & minimum-maksimum \\
\hline \multicolumn{2}{|l|}{ Yaş (yıl) } & 485 & $55,5 \pm 9,9$ & $20-84$ \\
\hline \multicolumn{2}{|c|}{ Hastalık süresi (ay) } & 476 & $103,0 \pm 91,3$ & $0-480$ \\
\hline \multicolumn{2}{|c|}{ HbA1c (\%) } & 474 & $7,8 \pm 106,3$ & $4,7-16,7$ \\
\hline \multicolumn{2}{|c|}{ Total kolesterol (mg/dl) } & 476 & $212,7 \pm 46,6$ & $64-371$ \\
\hline \multicolumn{2}{|c|}{ TG (mg/dl) } & 476 & $183,4 \pm 106,3$ & $28-929$ \\
\hline \multicolumn{2}{|l|}{ LDL-k (mg/dl) } & 477 & $130,7 \pm 37,1$ & $26-257$ \\
\hline \multicolumn{2}{|l|}{ HDL-k (mg/dl) } & 479 & $48,0 \pm 10,4$ & $22-93$ \\
\hline \multirow{2}{*}{ Bel çevresi (cm) } & Kadın & 286 & $107,7 \pm 14,4$ & $64-161$ \\
\hline & Erkek & 194 & $105,3 \pm 13,3$ & 74-168 \\
\hline \multicolumn{2}{|l|}{ BKİ $\left(\mathbf{k g} / \mathbf{m}^{2}\right)$} & 485 & $34,3 \pm 7,4$ & $21,2-64,4$ \\
\hline
\end{tabular}


yağ oranı ortalaması $\% 42,1 \pm 7,0$ iken erkeklerin ortalaması $\% 28,9 \pm 7,7$ ile aradaki fark anlamlıyd $(\mathrm{p}<0,001)$. Kadınların BKİ ortalaması $36,4 \pm 7,5 \mathrm{~kg} / \mathrm{m}^{2}$ iken erkeklerin $31,6 \pm 6,5 \mathrm{~kg} /$ $\mathrm{m}^{2}$, kadınların bel çevresi ortalaması $107,7 \pm 14,4 \mathrm{~cm}$ iken erkeklerin $105,3 \pm 13,3 \mathrm{~cm}$ bulundu. Egzersiz yapanların total vücut yağ oranı ortalaması $\% 35,5 \pm 10,0$ iken yapmayanların anlamlı yükseklikte $\% 37,7 \pm 9,5 \quad(\mathrm{p}=0,018)$ saptanırken, egzersiz yapanlarla yapmayanların BKİ ortalaması ve bel çevresi ortalaması arasında anlamlı fark bulunmadı $(\mathrm{p}=0,184, \mathrm{p}=0,574)$.
Beslenme uyumu olanlarla olmayanların total vücut yağ oranı ortalaması, BKİ ortalaması ve bel çevresi ortalaması arasında anlamlı fark yoktu ( $\mathrm{p}=0,237, \mathrm{p}=0,335, \mathrm{p}=0,529)$. İlaç kullanmayanlar, oral antidiyabetik kullananlar, insülin tedavisi alanlar ve kombine ilaç tedavisi alanlar arasında total vücut yağ oranları arasinda anlamlı fark bulunmadi $(\mathrm{p}=0,780)$. Hastalık süresi $<1$ yıl, 1-5 yıl, 5-10 yıl, $\geq 10$ yıl olanlar arasinda total vücut yağ oranları arasinda anlamlı fark yoktu $(\mathrm{p}=0,710)$. Olguların cinsiyete ve hastalık süresine göre alt ekstremite, üst ekstremite ve gövde yağ oranları Şekil l'de gösterilmiştir.

Tablo 2: Komplikasyon varlığına göre hastalık süresi, bel çevresi, AKŞ, BKİ, HbA1c, Total kolesterol, TG, HDL-k, LDL-k ortalamaları.

\begin{tabular}{|c|c|c|c|}
\hline & En az bir komplikasyon & Komplikasyonsuz & \multirow{2}{*}{$\mathbf{p}$} \\
\hline & Ort. \pm St.Sapma & Ort. \pm St.Sapma & \\
\hline Hastalık süresi (ay) & $121,8 \pm 96,6$ & $94,7 \pm 87,8$ & 0,004 \\
\hline Bel çevresi (cm) & $110,2 \pm 15,0$ & $105,1 \pm 13,1$ & $<0,001$ \\
\hline AKŞ (mg/dl) & $177,7 \pm 70,1$ & $163,8 \pm 64,1$ & 0,032 \\
\hline BKİ $\left(\mathbf{k g} / \mathbf{m}^{2}\right)$ & $35,7 \pm 8,4$ & $33,8 \pm 6,9$ & 0,008 \\
\hline HbA1c (\%) & $8,1 \pm 1,8$ & $7,8 \pm 1,9$ & 0,103 \\
\hline Total Kolesterol (mg/dl) & $212,3 \pm 49,2$ & $212,9 \pm 45,5$ & 0,912 \\
\hline TG (mg/dl) & $191,8 \pm 100,9$ & $179,6 \pm 108,6$ & 0,234 \\
\hline HDL-k (mg/dl) & $47,5 \pm 10,6$ & $48,3 \pm 10,4$ & 0,450 \\
\hline LDL-k (mg/dl) & $129,4 \pm 41,2$ & $131,3 \pm 35,3$ & 0,622 \\
\hline
\end{tabular}

Tablo 3: Diyabetin komplikasyonları ile bel çevresi, BKİ, total vücut yağ oranı, hastalık süresi ortalamaları.

\begin{tabular}{|c|c|c|c|c|c|c|c|c|c|}
\hline \multirow{2}{*}{\multicolumn{2}{|c|}{ Komplikasyonlar }} & \multicolumn{2}{|c|}{ Bel çevresi (cm) } & \multicolumn{2}{|c|}{ BKİ $\left(\mathrm{kg} / \mathrm{m}^{2}\right)$} & \multicolumn{2}{|c|}{ Total vücut yağ oranı (\%) } & \multicolumn{2}{|c|}{ Hastalık Süresi (Ay) } \\
\hline & & Ort \pm Ss & p & Ort \pm Ss & $\mathbf{p}$ & Ort. \pm Ss & $\mathbf{p}$ & Ort. \pm Ss & $\mathbf{p}$ \\
\hline \multirow{2}{*}{ Albuminüri } & Var & $110,0 \pm 13,3$ & \multirow{2}{*}{0,051} & $35,3 \pm 7,4$ & \multirow{2}{*}{0,327} & $37,4 \pm 9,4$ & \multirow{2}{*}{0,605} & $122,9 \pm 90,9$ & \multirow{2}{*}{0,084} \\
\hline & Yok & $106,3 \pm 14,0$ & & $34,3 \pm 7,5$ & & $36,7 \pm 9,8$ & & $100,5 \pm 91,1$ & \\
\hline \multirow{2}{*}{ Retinopati } & Var & $110,0 \pm 11,7$ & \multirow{2}{*}{0,292} & $36,0 \pm 8,0$ & \multirow{2}{*}{0,445} & $40,2 \pm 8,8$ & \multirow{2}{*}{0,311} & $124,5 \pm 95,4$ & \multirow{2}{*}{0,368} \\
\hline & Yok & $106,7 \pm 14,0$ & & $34,3 \pm 7,5$ & & $36,7 \pm 9,8$ & & $102,6 \pm 91,3$ & \\
\hline \multirow{2}{*}{ Nefropati } & Var & $113,4 \pm 16,0$ & \multirow{2}{*}{0,004} & $36,3 \pm 10,4$ & \multirow{2}{*}{0,119} & $36,1+11,2$ & \multirow{2}{*}{0,660} & $150,4 \pm 105,8$ & \multirow{2}{*}{0,001} \\
\hline & Yok & $106,2 \pm 13,7$ & & $34,2 \pm 7,2$ & & $36,8+9,6$ & & $99,4 \pm 89,1$ & \\
\hline \multirow{2}{*}{ Nöropati } & Var & $111,0 \pm 13,8$ & \multirow{2}{*}{0,031} & $36,3 \pm 7,4$ & \multirow{2}{*}{0,065} & $39,1 \pm 9,9$ & \multirow{2}{*}{0,092} & $112,4 \pm 91,9$ & \multirow{2}{*}{0,478} \\
\hline & Yok & $106,2 \pm 13,9$ & & $34,1 \pm 7,5$ & & $36,5 \pm 9,7$ & & $102,2 \pm 91,3$ & \\
\hline \multirow{2}{*}{$\begin{array}{l}\text { Koroner Arter } \\
\text { Hastalığı }\end{array}$} & Var & $107,1 \pm 13,6$ & \multirow{2}{*}{0,824} & $34,4 \pm 6,9$ & \multirow{2}{*}{0,979} & $37,0 \pm 9,2$ & \multirow{2}{*}{0,846} & $128,7 \pm 98,2$ & \multirow{2}{*}{0,047} \\
\hline & Yok & $106,7 \pm 14,0$ & & $34,4 \pm 7,5$ & & $36,8 \pm 9,8$ & & $100,0 \pm 90,0$ & \\
\hline \multirow{2}{*}{$\begin{array}{l}\text { Periferik Arter } \\
\text { Hastalığ } \mathbf{1}\end{array}$} & Var & $113,4 \pm 14,6$ & \multirow{2}{*}{0,024} & $36,4 \pm 8,1$ & \multirow{2}{*}{0,154} & $40,0 \pm 9,5$ & \multirow{2}{*}{0,092} & $104,0 \pm 70,7$ & \multirow{2}{*}{0,536} \\
\hline & Yok & $106,3 \pm 13,8$ & & $34,3 \pm 7,4$ & & $36,0 \pm 9,7$ & & $103,1 \pm 92,3$ & \\
\hline sVo & Var & $114,3 \pm 21,5$ & 0.513 & $35,5 \pm 10,8$ & & $36,4 \pm 6,6$ & & $180,0 \pm 60,0$ & \\
\hline svo & Yok & $106,7 \pm 13,9$ & 0,513 & $34,4 \pm 7,5$ & / & $36,8 \pm 9,8$ & 0,052 & $102,7 \pm 91,3$ & 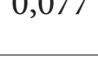 \\
\hline & Var & $133,0 \pm 24,5$ & 0.010 & $46,3 \pm 14,0$ & 0.041 & $42,7 \pm 7,6$ & 0.75 & $54,5 \pm 56,5$ & \\
\hline & Yok & $106,5 \pm 13,7$ & 8,010 & $34,3 \pm 7,3$ & & $36,7 \pm 9,8$ & 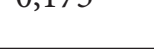 & $103,6 \pm 91,5$ & \\
\hline
\end{tabular}


Tablo 4: Cinsiyet, egzersiz, diyet, HbA1c, AKŞ, Total kolesterol, TG, LDL-k, HDL-k, komplikasyon ile total vücut yağ oranı ortalamaları ilişkisi.

\begin{tabular}{|c|c|c|c|}
\hline & & \multicolumn{2}{|c|}{ Total vücut yağ oranı (\%) } \\
\hline & & Ortalama \pm Ss & $\mathbf{p}$ \\
\hline \multirow{2}{*}{ Cinsiyet } & Kadın & $42,1 \pm 7,1$ & \multirow{2}{*}{$<0,001$} \\
\hline & Erkek & $28,9 \pm 7,6$ & \\
\hline \multirow{2}{*}{ Egzersiz } & Var & $35,5 \pm 10,1$ & \multirow{2}{*}{0,018} \\
\hline & Yok & $37,7 \pm 9,5$ & \\
\hline \multirow{2}{*}{ Beslenme uyumu } & Var & $36,2 \pm 9,9$ & \multirow{2}{*}{0,237} \\
\hline & Yok & $37,2 \pm 9,7$ & \\
\hline \multirow{2}{*}{ HbAlc } & Normal & $37,4 \pm 8,7$ & \multirow{2}{*}{0,767} \\
\hline & Yüksek & $36,8 \pm 9,8$ & \\
\hline \multirow{2}{*}{ AKŞ } & Normal & $38,2 \pm 10,7$ & \multirow{2}{*}{0,436} \\
\hline & Yüksek & $36,7 \pm 9,7$ & \\
\hline \multirow{2}{*}{ Total kolesterol } & Normal & $36,4 \pm 9,9$ & \multirow{2}{*}{0,402} \\
\hline & Yüksek & $37,2 \pm 9,7$ & \\
\hline \multirow{2}{*}{ TG } & Normal & $36,2 \pm 9,9$ & \multirow{2}{*}{0,228} \\
\hline & Yüksek & $37,3 \pm 9,5$ & \\
\hline \multirow{2}{*}{ LDL-k } & Normal & $36,6 \pm 9,8$ & \multirow{2}{*}{0,675} \\
\hline & Yüksek & $37,0 \pm 9,7$ & \\
\hline \multirow{2}{*}{ HDL-k (Kadın) } & Normal & $41,6 \pm 7,5$ & \multirow{2}{*}{0,210} \\
\hline & Düşük & $42,7 \pm 6,5$ & \\
\hline \multirow{2}{*}{ HDL-k (Erkek) } & Normal & $28,5 \pm 7,6$ & \multirow{2}{*}{0,233} \\
\hline & Düşük & $30,0 \pm 7,8$ & \\
\hline \multirow{2}{*}{ Komplikasyon } & Var & $38,5 \pm 9,8$ & \multirow{2}{*}{0,054} \\
\hline & Yok & $36,2 \pm 9,7$ & \\
\hline
\end{tabular}

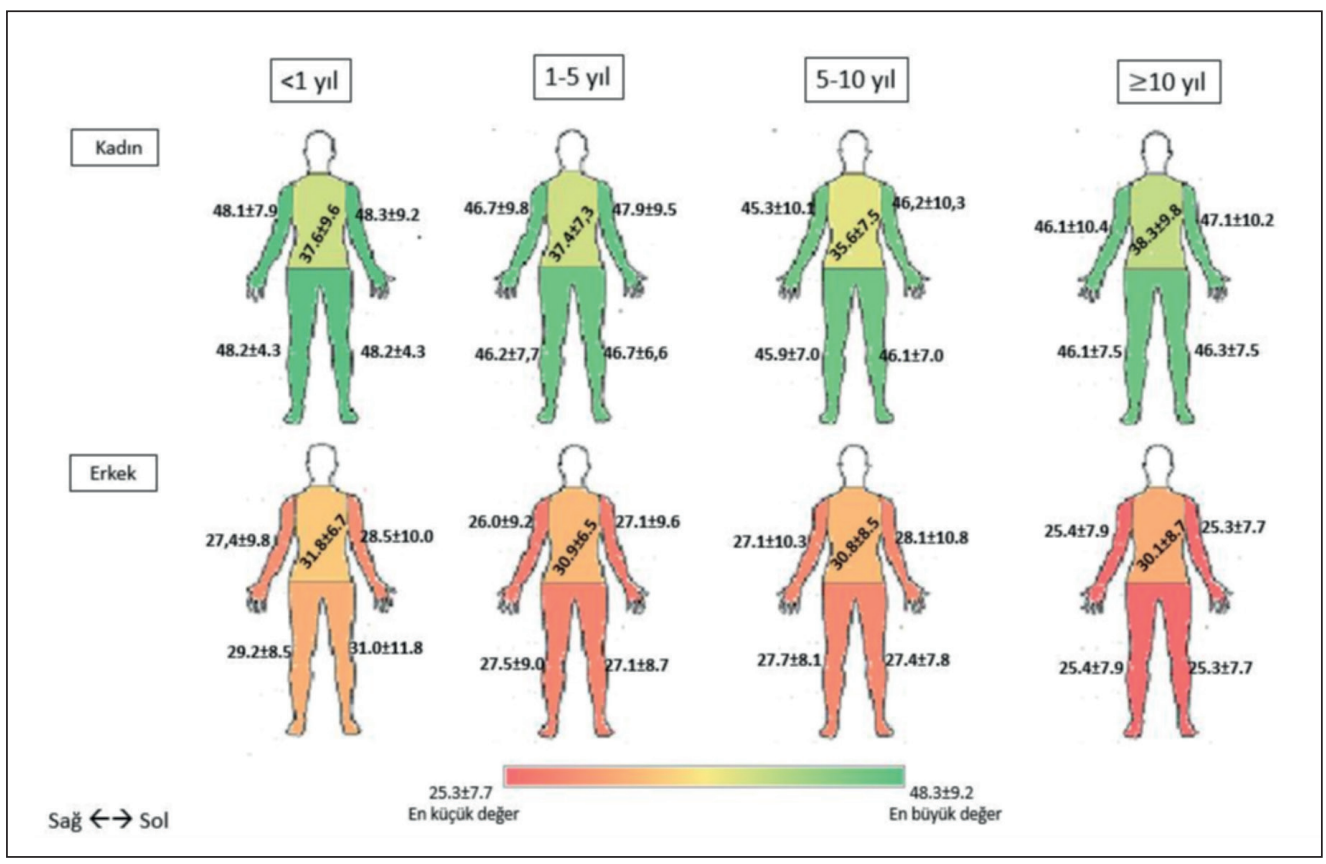

Şekil 1: Hastaların cinsiyete ve hastalık süresine göre alt ekstremite, üst ekstremite ve gövde yağ oranları (Şekil üzerinde bölgesel yağ oranı $\% \pm$ standart sapma olarak gösterilmektedir). 


\section{TARTISSMA}

Küresel Hastalık Yükü Obezite Grubu'nun 2015 yılı raporunda, dünyada obez nüfus 711,4 milyon (107,7 milyon çocuk ve 603,7 milyon yetişkin) civarındadır. Dünya Sağlık Örgütüne göre, 2016 yll için, yetişkinlerin \%39'u fazla kilolu, \%13'ü obezdir (21). Türkiye'de 2010 yllında yapılan TURDEP-II Çalışması'nda genel toplumda obezite sıklığı \%35 (kadınlarda: \%44, erkeklerde: \%27) olarak bulunmuștur (9). Diyabetli bireylerde obezitenin genel popülasyona göre daha yüksek olduğu bilinmektedir. Nural ve ark.'nın 2009 yılında yaptığı çalışmada hastaların $\% 45,5$ 'i obez, \%12,7'si morbid obez olup bu çalışmada da literatürle uyumlu olarak \%24,9 aşırı kilolu, \%68,5 obez hasta mevcuttur (22). Diabetes mellituslu hastalarının takiplerinde BKİ sıklıkla kullanılan bir ölçüt olup obezite sinıflamasının temelidir. $\mathrm{Bu}$ çalışmada DM hastalarının BKİ ortalaması $34,4 \pm 7,5$ $\mathrm{kg} / \mathrm{m}^{2}$ dir. Mamur'un 2016 yilında yaptığ 1 çalışmada $30,9 \pm 5,42 \mathrm{~kg} / \mathrm{m}^{2}$, Çıtıl ve ark.'nın çalışmasında $29,8 \pm 4,6$ $\mathrm{kg} / \mathrm{m}^{2}$, Gözaydın'ın çalışmasında $31,1 \pm 3,8 \mathrm{~kg} / \mathrm{m}^{2}$, Günalay ve ark.'nın çalışmasında $29,3 \pm 5,8 \mathrm{~kg} / \mathrm{m}^{2}$, Papadopoulos'un çalışmasında $30,4 \pm 5,2 \mathrm{~kg} / \mathrm{m}^{2}$ dir (23-27).

Çalışmamızda hastaların \%31,8'inde en az bir komplikasyon mevcut olup, \%12,0'inda albüminüri, \%2,5'inde retinopati, $\% 7,2$ 'sinde nefropati, \%9,5'inde nöropati, \%11,8'inde koroner arter hastalığı, \%5,4'ünde periferik arter hastalığ 1 , $\% 0,6$ 'sında SVO öyküsü, \%0,8'inde diyabetik ayak vardır. Nural ve ark.'nın çalışmasında ise hastaların \%56,9'unda hipertansiyon, \%25,9'unda koroner arter hastalığ 1 , $\% 8,6$ 'sinda nöropati ve $\% 1,7$ 'sinde retinopati olduğu görülmektedir (22). Kara ve ark.'nın 2009 yılında yaptığ 1 çalışmada kronik komplikasyon görülme oranı \%57 olarak saptanmıs olup en sık komplikasyon \%32 oranla retinopati ile hipertansiyondur. Olguların \%23,2'sinde kardiyak sorunlar ve \%20,3'ünde nöropati gelişmiştir (28).

Tip 2 diyabetiklerde hastalık süresi ile komplikasyonlar arasındaki ilişki birçok araştırmacı tarafından incelenmiş ve yapılan çalışmaların tamamına yakınında hastalık süresinde artış ile komplikasyon sıklığında yükselme görülmektedir (29-32). Çalışmamızda da en az bir komplikasyonu olan hastaların hastalık süresi ortalaması ile komplikasyonu olmayanların ortalaması arasında anlamlı farklılık bulunmuştur $(\mathrm{p}=0,004)$. Ayrıca nefropatisi olan hastaların hastalık süresi ortalaması, olmayanlardan anlamlı derecede yüksektir $(\mathrm{p}=0,001)$. Nadir ve ark.'nin yaptığ 1 çalışmada da bu çalışma ile benzer olarak diyabet süresi arttıkça nefropati sıklığında artış tespit edilmiştir (33). Fox ve ark. yaptıkları çalışmada koroner arter hastalığı ile Tip 2 DM süresi arasında anlamlı ilişki bildirmişlerdir (34). Taş ve ark. ise Ankara'da yaptıkları çalışmada, hastalık süresinin uzamasının retinopati riskini belirgin bir biçimde artırdığını saptamıştır (35). Hastalık süresi uzadıkça kan şekeri düzeyindeki dalgalanmalar metabolik durumu etkileyerek komplikasyonların ortaya çıkmasına zemin hazırlayabilir.
Tip 2 DM metabolik bir bozukluktur ve bu nedenle diyabetiklerin vücut bileșenlerini etkilemektedir. Yaygın kullanılan BKİ, vücut bileşenlerini incelemede yaygın olarak kullanılır ancak, kas ve yağ birikimi arasında ayrım yapma durumu sınırlıdır ve vücut şekli hakkında bilgi vermez. Herhangi bir şekilde BKİ'deki artış, yağ kütlesi, yağsız kütle veya her ikisindeki artışa bağlı olabilir. Bu da, BKİ’nin yağ dağılımını tahmin etmede kullanımını sınırlandırır $(36,37)$. Bel çevresi yaygın olarak merkezi yağlanmanın ölçütü olarak görülürveinsülin direnciileilişkisinin BKİ'den dahaiyi olduğu saptanmıştır (38). Buna karşın antropometrik ölçümlerin tek başına vücut kompozisyon değerlendirilmesinde yeterli olmadığı düşünülmüştür. Wedin ve ark. yaptığı çalışmada, obezitesi olan ve olmayan ergenlerde insülin direnci tahmininde bel çevresi veya BKİ'nin yetersiz kaldığını, bu değişkenlerin vücut yağ yüzdesiyle beraber değerlendirildiği durumlarda daha anlamlı sonuçlara ulaşıldığı bulunmuştur (39). Yine çocuklarda yapılan bir çalışmada vücut kompozisyonun BİA ile değerlendirmesinin beslenmenin değerlendirilmesinde önemli olduğuna değinilmektedir (40). Bu sebeple BİA güvenli, süratli, invaziv olmayan ve görece az maliyetli, etkili bir yöntem olarak kliniklerde sık kullanılmaya başlanmıştır (41).

Total vücut yağ miktarı ve vücut yağ dağılımı, diyabet ve kardiyovasküler hastalık riski ile ilişkili olup aynı zamanda bu hastalıkların gelişiminde nedensel bir rol oynayabilir. Tip 2 Diabetes Mellitus hastalarında her iki cinste de total vücut yağı ortalamalarının sağlıklı insanlardan daha yüksek olduğunu gösteren çalışmalar mevcuttur (42-44).

Çalışmamızda kadınların yaşa göre total vücut yağ oranları değerlendirildiğinde $\% 26,0^{\prime} 1$ aşırı yağll, $\% 62,3^{\prime} \ddot{u}$ obez olup erkeklerin \%37,2'si aşırı yağlı, \%46,0'1 obez olarak saptanmıștır. Kadınların total vücut yağ oranı ortalaması $\% 42,1 \pm 7,0$ iken erkeklerin ortalaması $\% 28,9 \pm 7,7$ oranında anlamlı oranda daha düşük bulunmuştur. Literatüre bakıldığında Tip 2 DM hastalarında vücut yağ dağılımı, sağlıklı bireylerden farklı olarak gövdede daha fazla ve bacaklarda daha az olma eğilimindedir $(45,46)$. $\mathrm{Bu}$ durumun nedeni bacak yağ dokusundaki depolama kapasitesindeki verimsizliğin, yağ deposunu abdominal yağ dokusuna yöneltme eğiliminde olmasıdır. Bacak ve gövde yağ kütlesi arasındaki bu fark insülin rezistansı için zemin hazırlayabilir. Tip 2 DM'de vücut yağ dağılımındaki bu farklılıklar Tip 2 DM'de yaygın olarak görülen insülin direncinin şiddetine katkıda bulunabilir (45). Kissebah'ın çalışmasında üst vücut segment obezitesi olan kadınlarda, alt vücut segment obezitesine sahip kadınlara göre plazma glukoz, insülin ve trigliserid düzeyleri anlamlı olarak daha yüksek bulunmuştur. Dolayısıyla vücut yağ dağılımı, glukoz intoleransı, hiperinsülinemi ve hipertrigliseridemi için önemli bir prognostik belirteç sunmaktadır. Bu durum farklı vücut yağ dağılımları ile ilişkili yağ hücrelerinin farklı morfolojisi ve metabolik davranışları ile ilişkili olabilir (47). 
$\mathrm{Bu}$ çalışmada literatüre benzer olarak erkeklerin vücut yağ dağılımı gövdede daha fazla ve bacaklarda daha azdır, ancak literatürden farklı olarak kadınlarda gövdede daha az ve bacaklarda daha fazla saptanmıştır. Bu durum, Türk vücut yapısındaki genetik farklılıktan kaynaklanıyor olabilir.

Düzenli egzersiz, bel çevresini ve insülin direncini azaltır, zayıflamayı destekler, dislipidemide olumlu etki sağlar, ayrıca diyabet ve diğer birçok önemli hastalık riskini azaltır (21). Bu çalışmada egzersiz yapanlarla yapmayanların total vücut yağ oranı ortalaması arasında istatistiksel olarak anlamlı fark vardır. Literatürde de 6 ay egzersiz yapan Tip 2 DM hastaları ile egzersiz yapmayan Tip 2 DM hastaları arasında total vücut yağ oranı ortalaması yönünden, bizim çalışmamızı destekler şekilde anlamlı fark tespit edilen çalışmalar mevcuttur $(9,47)$.

Sonuçta başarılı bir DM yönetimi için diyabete uygun beslenme, ilaç tedavisi, düzenli egzersiz hastanın kendi kendine hastalık takibi yapabilmesi ve dolayısıyla hasta eğitimi çok önemli yer tutmaktadır. Diyabetli hastaların takibi düzenli yapılmadığında total kolesterol, LDL-k, kan basıncı ve BKİ artmaktadır. Bu çalışmada DM hastalarının yaklaşık \%65'inin hem BKİ ölçümlerinde hem yağ analizi değerlendirmesinde obez olduğu, yarıdan fazlasının diyet ve egzersiz yapmadığı, egzersiz yapanlarda total vücut yağ oranının anlamlı düşük olduğu, en az bir komplikasyonu olanların hastalık süresi, bel çevresi, AKŞ, BKİ ortalamalarının anlamlı yüksek olduğunun saptanması, sadece medikal tedavinin DM kontrolünde yeterli olmadığını göstermiştir. Hastaların beslenmelerine uyması ve egzersiz yapması için daha sıkı takip edilmesi önemlidir. Hastaların egzersiz yapmasına olanak sağlayacak merkezlerin açılması, gerekirse obez hastaların evden alınarak bu tür merkezlere ulaşımının sağlanması, beslenme konusunda hastalara birebir eğitimler verilmesi de daha iyi bir diyabet kontrolü için faydalı olabilir. Obezite ve diyabet hastalığını yönetirken beraber değerlendirildiği durumlarda daha anlamlı sonuçlara ulaşılacağından her biri dikkate alınmalıdır.

\section{KAYNAKLAR}

1. Türkiye Endokrinoloji ve Metabolizma Derneği Diabetes Mellitus ve Komplikasyonlarının Tanı, Tedavi ve İzlem Kilavuzu. Bayt Matbaası, Ankara Mayıs 2018, 15-35. (http:// temd.org.tr/admin/uploads/tbl_kilavuz/201808141610192018tbl_kilavuz6c373c6010.pdf, Erişim Tarihi:15.03.2019)

2. Albright A. The public health approach to diabetes: Community and system aspects. The American Journal Of Nursing 2007;107(6): 39-42.

3. World Health Organization. Diabetes mellitus (http://www. who.int/mediacentre/factsheets/fs138/en/\#, Accessed Date: 09.04.2018)
4. Arısoy E. Birinci Basamağa Yönelik Tanı ve Tedavi Rehberi. Diabetes Mellitus. Ankara, Sağlık Bakanlığı Yayınları. 201203: 271- 275.

5. Yılmaz M, Bahçeci M, Büyükbese MA. Diabetes Mellitus'un Modern Tedavisi. İstanbul, Türkiye Diabet Vakfı Yayınları, 2003: 44- 49.

6. American Diabetes Association. Implications of The United Kingdom Prospective Diabetes Study. Diabetes Care 2003; 26: 28- 32.

7. Satman İ. Diabetes melltus'un tanı ve sinıflaması. Türkiye Klinikleri J Endocrin 2003;1(3):157-168.

8. World Health Statistics 2018: Monitoring health for the SDGs, sustainable development goals. Geneva: World Health Organization; 2018. Licence: CC BY-NCSA $3.0 \quad$ IGO. (https://apps.who.int/iris/bitstream/hand le/10665/272596/9789241565585-eng.pdf?ua=1, Accessed Date.15.03.2019)

9. Satman I, Omer B, Tutuncu Y, Kalaca S, Gedik S, Dinccag $\mathrm{N}$, et al; TURDEP-II Study Group. Twelve-year trends in the prevalence and risk factors of diabetes and prediabetes in Turkish adults. Eur J Epidemiol 2013;28:169-180.

10. Huang CY, Ting WH, Lo FS, Tsai JD, Sun FJ, Chan CI, Chiang YT, Lin CH, Cheng BW, Wu YL, Hung CM, Lee YJ. Factors associated with diabetic nephropathy in children, adolescents, and adults with type 1 diabetes. J Formos Med Assoc 2017;116(12):924-932.

11. Janka HU, Plewe G, Riddle MC, et al. Comparison of basal insulin added to oral agents versus twice-dily premixed insulin as initial insulin therapy for type 2 diabetes. Diabetes Care 2005; 28: 254-259.

12. Roman SH, Harris MI. Management of diabetes mellitus from a public health perspective. Endocrinol Metab Clin North Am 1997;26:443-474.

13. Smith SR. Obesity: The endocrinology of obesity. Endocrinol Metab Clin North Am 1996; 25: 921-42.

14. Cnop M, Landchild MJ, Vidal J, Havel PJ, Knowles NG, Carr $\mathrm{DR}$ et al. The concurrent accumulation of intra-abdominal and subcutaneous fat explains the association between insulin resistance and plasma leptin concentrations: distinct metabolic effects of two fat compartments. Diabetes 2002; 51: 1005-1015.

15. Wagenknecht LE, Langefeld CD, Scherzinger AL, Norris JM,Haffner SM, Saad MF, Bergman RN. Insulin sensitivity, insulin secretion, and abdominal fat: The Insulin Resistance Atherosclerosis Study (IRAS) Family Study. Diabetes 2003; 52: 2490-2496.

16. Utzschneider KM, Carr DB, Hull RL, Kodama K, Shofer JB, Retzlaff BM, Knopp RH, Kahn SE. Impact of intra-abdominal fat and age on insulin sensitivity and beta-cell function. Diabetes 2004; 53: 2867-2872.

17. Kuk JL, Katzmarzyk PT, Nichaman MZ, Church TS, Blair SN, Ross R. Visceral fat is an independent predictor of all-cause mortality in men. Obesity 2006; 14: 336-341 
18. Lukaski HC. Soft tissue composition and bone mineral status: Evaluation by dual-energy X-ray absorptiometry. J Nutr 1993;123 (2 Supply): 438-443.

19. Johnston CC, Hui SL, Longcope C. Bone mass and sex steroid concentrations in postmenopausal Caucasian diabetics. Metabolism 1985;34(6): 544-550.

20. Tanita Scales: Understanding your Measurement. (https://tanita.eu/tanita-academy/understanding-yourmeasurements, Accessed date: 20.03.2019)

21. TEMD Obezite, Lipid Metabolizması, Hipertansiyon Çalışma Grubu Obezite Tanı Ve Tedavi Kılavuzu, 2018, Ankara. (http:// temd.org.tr/admin/uploads/tbl_kilavuz/OBEZITE2017_web. pdf, Erişism Tarihi:20.03.2019)

22. Nural N, Hindistan S, Gürsoy AA, Bayrak N. Bir Sağlık Ocağına Başvuran Tip 2 Diabetes Mellitus Tanılı Hastaların Epidemiyolojik Özellikleri ve Prognozu. TAF Preventive Medicine Bulletin 2009:8(4):297-306.

23. Mamur, A. (2016). Tip 2 diyabetes mellitusta kullanılan tedavi yöntemlerine ve vücut kitle indekslerine göre hedef glikozillenmiş hemoglobin düzeylerine ulaşma oranları. Aile Hekimliği Anabilim Dalı, Tıpta Uzmanlık Tezi, 2016. (http://openaccess.ogu.edu.tr:8080/xmlui/bitstream/ handle/11684/1265/ahmet\%20mamur\%20tez\%2010125370. pdf? sequence=1\&isAllowed=y, Erişim Tarihi:20.03.2019).

24. Çıtıl R, Öztürk Y, Günay O. Kayseri il merkezinde bir sağlık ocağına başvuran diyabetik hastalarda metabolik kontrol durumu ve eşlik eden faktörler. Erciyes Tıp Dergisi 2010; 32(2):111-122.

25. Gözaydın M, Duygun T, Saygılarlı İ. Tip 2 diabetes mellituslu hastalarda glisemi ile yaşam kalitesi arasındaki ilişki. Medikal Network Klinik Bilimler \& Doktor, 2003; 9: 670- 674.

26. Günalay S, Taşkıran E, Demir B, Erdem S, Mergen H, Akar H. Tip 2 diyabetes mellitus hastalarında tedavi yöntemleri, glisemik kontrol ve diyabet komplikasyonları ile depresyon ve anksiyete riski arasındaki ilişki. FNG \& Bilim Tıp Dergisi 2016;2(1):16-19.

27. Papadopoulos A, Kontodimopoulos N, Frydas A, Ikonomakis E, Niakas D. Predictors of health-related quality of life in type II diabetic patients in Greece. BMC Public Health 2007;7:186.

28. Kara K, Çınar S. Diyabet bakım profili ile metabolik kontrol değişkenleri arasındaki ilişki. Kafkas Tıp Bilimleri Dergisi 2011;2:57-63.

29. Segato T, Midena E, Grigoletto F, Zucchetto M, Fedele D, Piermarocchi S, et al. The epidemiology and prevalence of diabetic retinopathy in the Veneto region of north east Italy. Veneto Group for Diabetic Retinopathy. Diabet Med 1991;8:11-16.

30. Salman S, Özer E, Sargin M. Ten year follow up results of microvascular complications in İstanbul. Black Sea Diab Meeting. Poster, İstanbul, 1997.

31. Hatemi H. Diabet komplikasyon istatistikleri. 1. bask1, İstanbul: Servier Araştırma Grubu Yayınları; 1998.

32. Altunoğlu EG. Tip 2 Diabetes mellituslu hastalarda diyabet süresi ve HBA1c düzeyleri ile depresyon, anksiyete ve yeti yitimi arasındaki ilişki. Istanbul Tıp Dergisi 2012;13:3.
33. Nadir I, Topçu S, İçağasığlu S, Yıldırım N. Tip II diabetes mellitusta nefropati gelişiminde risk faktörleri. Van Tip Dergisi 2003;10 (3):65-68.

34. Fox CS, Sullivan L, D'Agostino RB, Wilson PW; The Framingham Heart Study. The significant effect of diabetes duration on coronary heart disease mortality. Diabetes Care 2004;27(3):704-708.

35. Taş A, Bayraktar MZ, Erdem Ü, Sobacı G, Uçar M. Diyabetik hastalarda retinopati sıklığı ve risk faktörleri, Gülhane Tıp Dergisi 2005; 47: 164-174.

36. Gasier HG, Hughes LM, Young CR, Richardson AM. Comparison of body composition assessed by dual-energy X-ray absorptiometry and BMI in current and former U.S. navy service members. PLoS ONE 2015;10:e0132157.

37. Shah NR, Braverman ER. Measuring adiposity in patients: The utility of body mass index (BMI), percent body fat, and leptin. PLoS ONE 2012;7:e33308.

38. Gomez-Peralta F, Abreu C, Cruz-Bravo M, Alcarria E, Gutierrez-Buey G, Krakauer NY, Krakauer JC. Relationship between "a body shape index (ABSI)" and body composition in obese patients with type 2 diabetes. Diabetol Metab Syndr 2018;10:21.

39. Wedin WK, Diaz-Gimenez L, Convit AJ. Prediction of insulin resistance with anthropometric measures: Lessons from a large adolescent population. Diabetes Metab Syndr Obes 2012;5:219-225.

40. Özçetin M, Khalilova F, Kılıç A. Beslenme durumunun değerlendirilmesinde sıra dışı bir yöntem: BİA. Çocuk Dergisi 2017;17(2):61-66.

41. Guida B, Trio R, Nastasi A, Laccetti R, Pesola D, Torraca S, Memoli B, Cianciaruso B. Body composition and cardiovascular risk factors in pretransplant hemodialysis patients. Clin Nutr 2004;23:363-372.

42. Owolabi LF, Adebisi SS, Danborno B, Buraimoh AA. Comparative evaluation of body composition analysis in type-2 diabetes mellitus patients and healthy Nigerians using bioelectric impedance analysis technique. Nigerian Journal of Basic and Clinical Sciences 2016;13(1):13.

43. Solanki JD, Makwana AH, Mehta HB, Gokhale PA, Shah CJ. Body composition in type 2 diabetes: Change in quality and not just quantity that matters. Int J Prev Med 2015;6:122.

44. Baltadjiev A, Baltadjiev G. Assessment of body composition of male patients with type 2 diabetes by bioelectrical impedance analysis. Folia Medica 2011;53(3):52-57.

45. Azuma K, Heilbronn LK, Albu JB, Smith SR, Ravussin E, Kelley DE; Look AHEAD Adipose Research Group. Adipose tissue distribution in relation in insulin resistance in type 2 diabetes mellitus. Am J Phys Endo Met 2007;293(1):E435-442.

46. The Long Term Intervention with Pravastatin in Ischaemic Disease (LIPID) Study Group. Prevention of cardiovascular events and death with pravastatin in patients with coronary heart disease and a broad range of initial cholesterollevels $\mathrm{N}$ Engl J Med 1998;5:339:1349-1357.

47. Kissebah AH, Vydelingum N, Murray R, Evans DJ, Kalkhoff RK, Adams PW. Relation of body fat distribution to metabolic complications of obesity. J Clin Endocrinol Metab 1982;54(2):254-260. 